\title{
¿Hay una objetividad especifica para la historia?
}

\author{
Is there a specific objectivity for history?
}

\author{
Rosa E. Belvedresi a \\ E-mail: rosabelvedresi@gmail.com \\ https://orcid.org/0000-0002-9769-0700 iD
}

a Universidad Nacional de La Plata, Facultad de Humanidades y Ciencias de la Educación, Departamento de Filosofía, Buenos Aires, Argentina

\section{RESUMEN}

En este artículo nos proponemos realizar un análisis de la objetividad del conocimiento histórico atendiendo a sus especificidades como disciplina científica. Para ello, mostraremos que es insostenible la idea de objetividad absoluta $y$, en su lugar, propondremos el concepto de una objetividad situada. Esta objetividad tiene que ver con los criterios vigentes en una disciplina científica y con sus prácticas propias. Consideramos que el conocimiento histórico objetivo no niega la influencia de los sujetos en su producción y justificación, sino que procura atender a los efectos que esa interferencia pueda ocasionar. También veremos las conclusiones que pueden extraerse sobre la condición de sujetos que poseen los objetos del conocimiento histórico. Para nuestro análisis vamos a distinguir entre la objetividad que se refiere al comportamiento del sujeto que investiga (la historiadora) y la que se refiere al producto del conocimiento (las interpretaciones históricas). Finalmente, señalaremos que la objetividad es objeto de críticas y revisiones en los debates históricos.

\section{ABSTRACT}

This work focuses on the objectivity of historical knowledge, attending to the specificities of this scientific discipline. For this we will show that the idea of an absolute objectivity is unsustainable and propose a situated objectivity. Such objectivity has to do with the accepted criteria in a given scientific discipline and with its established practices. We will show that objective historical knowledge does not deny the influence of human subjects on its production and justification, but rather tries to attend to the effects that this interference may cause. We will also discuss the condition of human subjects that is characteristic of the objects of historical knowledge. For our analysis, we will distinguish between objectivity that refers to the behavior of the human subject who investigates (the historian) and what refers to the product of knowledge (historical interpretations). Finally, we will point out that objectivity may be subject to criticism and revision in historical debates.

\section{PALABRAS CLAVE}

Conocimiento histórico; Objetividad; Sujeto

\section{KEYWORDS}

Historical knowledge; Objectivity; Subject 


\section{Introducción: hablar de objetividad}

En este trabajo nos concentraremos en el tema de la objetividad del conocimiento histórico, para lo cual intentaremos mostrar cuál es la forma más adecuada de abordarlo atendiendo a las especificidades de esa disciplina científica. En nuestra caracterización de la objetividad nos detendremos en sus dos modalidades básicas: aquella que se aplica al sujeto que investiga (la historiadora) y la que se refiere al producto del conocimiento resultado de esa investigación (las descripciones históricas).

Analizar la objetividad del conocimiento histórico obliga a revisar una de las grandes cuestiones de la epistemología: qué entendemos por conocimiento objetivo y cómo es posible conseguirlo. En una amplia formulación general, la objetividad puede entenderse como la característica que posee aquel conocimiento que da cuenta de la realidad. Definida de manera absoluta, la objetividad supone que no hay ninguna interferencia generada por el sujeto en el conocimiento producido (DASTON; GALISON 2007, p. 17). Así, una descripción objetiva nos diría lo que realmente es, tal y como realmente es, con independencia del sujeto que formule la descripción o de las condiciones en las que la genere. Habría aquí una estrecha vinculación entre objetividad y una noción de representación mimética en la medida en que una descripción objetiva sería aquella que se correspondería punto por punto con lo que ella describe. A ello se agrega también una pretensión realista según la cual el objeto de conocimiento existiría con independencia del sujeto que lo conoce, no siendo, por lo tanto, su creación. De ahí que el conocimiento objetivo versaría sobre un objeto real cuya naturaleza o existencia no se modificaría al ser conocido ni dependería de ello para existir (AGAZZI 2014, p. 54-5; KUUKKANEN 2015, p. 169).

Así formulada la objetividad nos pone frente a un conocimiento "sin sujeto" (POPPER 1974). Los sujetos descubrirían sus objetos (materiales o ideales) de conocimiento 
y tratarían de formular descripciones fieles sobre ellos sirviéndose de herramientas lingüísticas y mentales. Pero, ¿podríamos nosotros asumir tal objetividad absoluta? Desde nuestra posición como sujetos, estamos involucrados en la producción de conocimiento y nos resulta imposible asumir una perspectiva como la del "ojo de Dios" (PUTNAM 2006). Hace falta una noción de objetividad algo más sofisticada para dar cuenta del conocimiento como un proceso que es el resultado de ciertos comportamientos de los sujetos inmersos en la actividad de conocer.

Un modo alternativo de tratar la objetividad sería ponerla en relación con la intersubjetividad. Antes que considerarlo como una descripción del mundo sin que medie la interferencia de los sujetos, el conocimiento objetivo sería aquel en el que los sujetos podrán estar de acuerdo porque su comprobación es posible para cualquiera que quiera realizarla (AGAZZI 2014, p. 57-8; KLIMOVSKY 1994, p. 50). Así, el dato del diámetro de la tierra es objetivo porque está intersubjetivamente justificado, puesto que cualquiera puede comprobarlo si dispone del conocimiento previo y el instrumental adecuado. Estas dos condiciones son vitales a la hora de entender la objetividad, dado que sitúan el concepto en el estado del conocimiento en determinado momento y en el uso del instrumental y los procedimientos aceptados por una disciplina científica (AGAZZI 2014, p. 333 y 410-411). Además, el desarrollo de algunas ramas de la ciencia (como la física cuántica) ha obligado a admitir que incluso la actividad misma de conocer puede provocar cambios en el objeto estudiado. Es decir, al intentar conocer, el sujeto interfiere de alguna manera con el objeto bajo estudio.

Lo antedicho nos lleva a pensar que, en lugar de una objetividad absoluta, sólo es posible pensar en términos de una objetividad situada y ello por las siguientes razones: en primer lugar, porque el conocimiento objetivo es tal sólo si se ajusta a los criterios vigentes en una disciplina científica determinada y resulta de aquellas prácticas que le son propias; 
en segundo lugar, porque el conocimiento objetivo no niega la influencia de los sujetos en su producción y justificación, sino que procura atender a los efectos que esa interferencia pueda ocasionar. Sólo cuando se reconocen estas condiciones, la objetividad puede seguir funcionando como un ideal regulativo del conocimiento científico.

\section{Aproximación preliminar al problema}

El planteo general de la objetividad en las ciencias admite ciertas modulaciones particulares cuando abordamos el caso de las ciencias humanas y sociales $y$, en particular, de la historiografía. Las denominadas Geisteswissenschaften han reivindicado para sí la condición de ser "subjetivas", lo que ha provocado muchas respuestas críticas, pues, ¿cómo podría hablarse de un conocimiento objetivo en este caso? (SCHUTZ 1974; para las críticas clásicas, ver ABEL 1964 y NAGEL 2006). Las "ciencias culturales" o "históricas" tendrían una metodología propia para dar cuenta de los fenómenos que estudian.

En un marco de expansión del positivismo, a comienzos del siglo XX, la historia ofrecía resistencia para adecuarse a un monismo metodológico que suponía la existencia de "hechos históricos" que podían ser explicados bajo la misma estructura lógica de las ciencias naturales. El énfasis en la tesis de que la historia sólo se ocupaba de acontecimientos únicos e irrepetibles o que concentraba su interés en individuos sin buscar las causas de lo sucedido ni pretender explicarlo hizo que se tomara la disciplina como el ejemplo que impugnaba la propuesta del monismo metodológico naturalista. Está claro que esa caracterización de la historia es, por lo menos, limitada. Nada impide que la historiadora formule conceptos generales, compare sucesos históricos en busca de semejanzas o establezca conexiones explicativas que puedan ser útiles para otros casos. Sin embargo, la caracterización de la historia como ciencia de lo individual fue usada para distinguirla de las ciencias naturales 
(o de otras ciencias sociales que admitían un tratamiento experimental o estadístico, como la sociología o la psicología del siglo XIX).

Autores como Dilthey defendieron el carácter empírico de la historia $y$, por lo tanto, la exigencia de que se ajuste a los mismos principios que cualquier otro conocimiento empírico. Pero, advertía Dilthey, los fenómenos que estudiaba la historia no eran comparables a los de las ciencias naturales. El objeto del historiador eran manifestaciones vitales, es decir, productos humanos que poseían la doble característica de ser empíricamente constatables $\mathrm{y}$, también, ser portadores de significados. Una interpretación adecuada de esos objetos requería de parte del historiador el despliegue de habilidades que no le eran requeridas al científico natural y que se derivaban de las formas elementales de la comprensión en la vida cotidiana (DILTHEY 1986). Podría argumentarse que un científico natural también puede estar interesado en el significado de los fenómenos que estudia. Por ejemplo, un químico puede preguntarse qué significa que suceda $x$ (el cambio de color en un pedazo de papel) e intentar vincularlo con y (la presencia de determinada sustancia); así como un físico debe interpretar el significado del movimiento de una aguja en un instrumento. Pero no es esa la noción de significado que se pone en juego en la hermenéutica diltheyana, según la cual el significado de una manifestación vital (digamos, una pintura) resulta de la compleja interacción entre elementos psicológicos de la subjetividad del autor (sus intenciones, deseos, etc.) y aquellos que provienen del contexto (cultural y social) en el que la manifestación se produce.

En las ciencias sociales y humanas, científicos y objeto de estudio participan de la comunidad humana. Incluso cuando se trate de personas que pertenezcan a ámbitos culturales completamente distintos o estén separadas por siglos, todas comparten la experiencia de formar parte de un mundo socialmente articulado. Todas poseen la capacidad de producir 
y entender significados culturales, de anticipar conductas de otras personas, de asignarles sentido y responder a él, de seguir pautas de comportamiento instituidas, etc.:

[s]i observamos un proceso natural, la cuestión de producir evaluaciones significativas ni siquiera se plantea; si observamos la historia, esto surge de modo compulsivo, no sólo a causa de su tema (seres conscientes que realizan evaluaciones) sino también porque el observador es por su misma naturaleza moral e intelectual, una criatura con esas compulsiones (THOMPSON 1981, p. 347). ${ }^{1}$

Esta característica especial de las ciencias sociales y humanas involucra dos elementos adicionales a tener en cuenta para evaluar su objetividad. Primero, los investigadores en estas ciencias pueden involucrarse afectivamente con su objeto en la medida en que éste es otro ser humano (como veremos más adelante, no sólo pueden involucrarse afectivamente, sino que, en ciertos casos, deben hacerlo). Segundo, la condición humana del objeto también puede hacer que éste reaccione a la situación de conocimiento

En 1985, el historiador británico Daniel James estaba interesado en estudiar los orígenes del peronismo, para lo cual decidió investigar a quienes habían sido obreros de los frigoríficos de Berisso (una ciudad de la provincia de Buenos Aires, Argentina). Desde esa zona partieron muchos de los trabajadores que formaron parte de la masiva movilización popular del 17 de octubre de 1945 hacia la ciudad de Buenos Aires que pidió la liberación de Perón, preso por el gobierno militar, del cual había formado parte en sus comienzos. En su búsqueda de informantes que le proporcionaran datos y relatos de vivencias de esas circunstancias, James conoció a doña María, una mujer que había sido delegada en el frigorífico Swift. Al relatar su experiencia con ella, dice James: "yo había quedado impresionado por su claridad y su aparentemente buena memoria" (JAMES 1992, p. 8, cursivas agregadas). El historiador decide, finalmente, entrevistarla varias veces a lo 
largo de nueve meses $y$, con el material que obtuvo en esos encuentros, elaboró su libro (JAMES 2004).

Si ahora vemos esa relación de conocimiento entre el investigador y la investigada desde el lado del objeto, doña María, se hará evidente cómo la situación de entrevista generó un contexto particular que afectó su comportamiento. Dice James: "Doña María me estaba diciendo y relatando la historia de su vida, reconstruyendo su pasado en una forma selectiva que podía, simultáneamente, ser legítima para mí y tener sentido para ella misma" (JAMES 1992, p. 9, cursivas agregadas). Es decir, James se da cuenta de que doña María buscaba de alguna manera su aprobación y de que su relato podría estar estructurado en una forma que apuntara más a legitimar su historia que a ser un simple recitado de los sucesos de los que había participado.

Lo que sucedió en las entrevistas que James le realizó a doña María podría decirse que se da en todas las investigaciones sociales que involucren comunidades actualmente existentes o individuos coetáneos con quienes la investigadora social interactúa. En esas condiciones, la situación de investigación genera conductas que no se producirían de otro modo. Las respuestas de un individuo en una entrevista o el comportamiento de quienes se saben filmados no serán espontáneos. Es probable que, incluso sin desearlo, busquen la aprobación de los investigadores, actuando de la manera en que, creen, se espera que lo hagan. Como lo muestra el ejemplo de doña María y su búsqueda de reconocimiento por parte del historiador, el conocimiento histórico, así como la sociología o la antropología cultural, también puede provocar modificaciones en su objeto. Esto habrá de ocurrir en aquellas modalidades del conocimiento histórico que no se concentran únicamente en el pasado lejano, que pueden abordar a partir de documentos o reliquias, sino también en un pasado reciente, del cual aún quedan personas vivas que pueden dar testimonio de lo sucedido. En estos casos, objeto y sujeto de conocimiento son contemporáneos. 
Pero el conocimiento histórico también produce alteraciones en quienes consumen sus productos; muy especialmente en aquellas personas y comunidades que se piensan continuadoras o descendientes de otras que habitaron en el pasado objeto de estudio. De esta manera, por medio de la investigación histórica, los individuos actuales pueden llegar a reconocer sus vinculaciones con antecesores que antes ni siquiera reconocían como tales. Así, por ejemplo, al referirse a la denominada "historia desde abajo", dice Sharpe que ella ofrece "el medio de restituir a ciertos grupos sociales una historia que podría haberse dado por perdida o de cuya existencia no eran conscientes" (SHARPE 1993, p. 55-56).

\section{Un ejemplo}

En 1999, una expedición de científicos internacionales descubrió tres momias en perfecto estado de conservación en el volcán del Llullaillaco (noroeste de Argentina, cerca de la frontera con Chile). Las momias tienen una antigüedad estimada en 500 años y se preservan actualmente en el Museo de Alta Montaña de la provincia de Salta, en el cual se exponen de manera individual y rotativa bajo estrictas condiciones de conservación. Los investigadores hallaron los cuerpos momificados de un niño, una niña y una joven, bellamente vestidos, rodeados de objetos valiosos, que habían sido entregados como sacrificio en el marco de una ceremonia religiosa organizada por el Imperio Inca (CERUTI 2012, p. 98).

El descubrimiento de esos cuerpos humanos congelados confirma las teorías existentes sobre la práctica conocida como "capacocha", en la cual se ofrendaban niños y objetos a los dioses en el marco de una compleja interrelación social y política (CERUTI 2003, MIGNONE 2015). Las momias fueron estudiadas de manera empírica con diversas técnicas provenientes de la medicina (estudios microbiológicos, odontológicos, radiológicos, etc. ) y, complementariamente, con análisis sobre las telas con las que estaban vestidos y sobre la disposición espacial de los 
cuerpos en relación con los otros objetos encontrados. Sin embargo, persisten otros interrogantes sobre las muertes de los niños que no pueden responderse sólo con estos estudios empíricos: ¿qué condiciones las rodearon?, ¿quiénes y cómo las provocaron?, ¿cómo eran las relaciones familiares y sociales que los condujeron a ese desenlace? y, finalmente, ¿cuál es el sentido de sus muertes en la cima de una montaña helada a la que habrían Ilegado luego de un largo viaje?

Esta práctica sacrificial parecerá cruel e, incluso, absurda a personas de nuestra época. Para salvar ese extrañamiento, los investigadores deben comprender el culto religioso de las culturas precolombinas que constituye el trasfondo de esas muertes y que podría explicarlas. El análisis de los restos y los utensilios encontrados hacen posible que los Incas puedan contar "su propia historia" y se develen aspectos de su vida cotidiana que de otro modo sólo serían abordados a partir de "fuentes escritas por cronistas españoles" (CERUTI 2012, p. 94), es decir, desde la perspectiva del conquistador blanco. Para lograr una interpretación objetiva de la muerte de estos jóvenes (cuyas causas naturales podrán determinarse clínicamente), debe entenderse el ceremonialismo inca, del cual esas muertes eran una parte fundamental. Debemos comprender estas prácticas sacrificiales en sus propios términos, evitando una lectura anacrónica o etnocéntrica. Para ello, es necesario rescatar aquellos aspectos de "la religiosidad precolombina que siguen siendo ignorados o negados sobre la base de prejuicios" (CERUTI 2012, p. 99). Los niños del Llullaillaco, aunque hayan desaparecido siglos atrás, siguen siendo humanos y, por tanto, seres culturales que poseían creencias religiosas, formaban parte de una estructura social, se vinculaban a través de relaciones familiares. Es decir, eran sujetos activos enmarcados en sus propios contextos socioculturales. Como tales, podrán despertar en quienes los investigan sentimientos de simpatía, pues esos niños fueron considerados "mensajeros a los dioses", condición que deberá ser "honrada con la verdad y el respeto que ellos merecen" (p. 99). 
A diferencia del ejemplo de doña María, quien interactúa directamente con el investigador, en el caso de los niños puede argumentarse que el estudio de sus cuerpos momificados no impactaría en los grupos sociales originales, puesto que quienes realizaron las prácticas religiosas que los tuvieron como protagonistas ya no están vivos. Pero el descubrimiento y su posterior interpretación sí han modificado la comunidad actual, se trate tanto de los sobrevivientes de los grupos originarios como del resto de la población de la región. Acerca del efecto del descubrimiento sobre la comunidad, en opinión de una de las investigadoras que participó de la expedición: "es interesante considerar el sustancial impacto de las investigaciones sobre las momias infantiles del Llullaillaco en la valoración del aporte de las culturas andinas a la identidad salteña", que, hasta entonces, sólo "se cimentaba en torno al legado hispano" (CERUTI 2012, p. 95-96). Según esta misma investigadora, el estudio de las momias habría jugado una "parte fundamental" en "los procesos de re-construcción de la identidad indígena ocurridos en el noroeste de Argentina durante la última década" (CERUTI 2012, p. 97).

Ahora, si consideramos el estudio de los niños momificados desde la perspectiva de quienes se sienten sucesores de la cultura a la que pertenecían, también puede verificarse que el mismo tiene un efecto en ellos, en quienes ha generado, por ejemplo, reacciones críticas. Las comunidades originarias vinculan el hallazgo y la exhibición de las momias a su inserción marginal en la sociedad actual y consideran que su identidad cultural no es respetada en la medida en que las momias (que reclaman como propias) son expuestas sin contar con su acuerdo. Por este motivo, las comunidades originarias de Salta han exigido la restitución de los niños momificados y demandado la prohibición de su exhibición. Este caso se inserta en el movimiento mayor de pedidos de restitución de los restos que se exhiben como reliquias en museos de Argentina, encabezados por diversas comunidades originarias. Ello ha motivado la devolución de muchos de esos restos, en el marco del respeto a la diversidad cultural, consagrada en la 
Constitución Nacional (artículo 75, inciso 17). ${ }^{2}$ Como este caso muestra, el estudio de los niños momificados reverbera en el presente de los investigadores, la sociedad local y nacional y las comunidades originarias sin que la distancia de 500 años parezca ser relevante.

Desde un punto de vista que podemos calificar laxamente como "naturalista" (por cuanto toma como modelo de conocimiento a las ciencias naturales), las momias descubiertas pueden ser estudiadas empíricamente por la biología, la arqueología, la física o la química. Pero si este punto de vista fuera exclusivo, se perdería el sentido que pudo revestir la práctica de exponer a estos niños a las extremas condiciones climáticas que provocaron su muerte. La interpretación del hecho requiere el despliegue de técnicas de estudio y de interpretación que son propias de la disciplina histórica. Ahora bien, ¿cuándo podríamos decir que la historia nos ha provisto de una interpretación "objetiva" del suceso que se pretende entender?

\section{La objetividad en la ciencia histórica}

Antes de intentar responder a la pregunta que hemos dejado planteada al final del párrafo anterior, debemos explicitar los dos sentidos en que puede entenderse el término "interpretación". En un sentido general, "interpretación" refiere a la búsqueda de significado que vuelva comprensible un elemento empírico, sea éste un texto, una pieza de arcilla, un hueso, o también el resto material de un proceso natural (fósiles), la evidencia empírica de la ocurrencia de un fenómeno determinado (cenizas), una imagen o sonido en un aparato, etc. En un sentido específico, "interpretación" designa el producto de la tarea que la historiadora realiza al intentar dar cuenta del pasado. El sentido general será común a las ciencias sociales y a las naturales, pues éstas también tratan de interpretar (por ejemplo, el patrón que muestra una imagen para determinar el comportamiento de la luz). Pero el sentido específico es propio de la historia científica. Por "interpretación" vamos
2 La cuestión de la restitución de restos excede el marco de este trabajo. Para una descripción general del marco legal de este $y$ otros casos en Argentina, véase (COSMAI; FOLGUERA; OUTOMURO 2013). 
a entender, en este segundo sentido, la producción de una descripción explicativa que da cuenta de una parte del pasado. Así entendida, la interpretación puede contener, también, una explicación, pues guía la forma en la que algo puede ser explicado. Así, si se interpreta un determinado evento del pasado como una "revolución", la explicación que se pueda proveer de él dará cuenta del cambio radical de las instituciones políticas, identificará a determinados actores sociales como agentes revolucionarios y establecerá el contexto contra el cual esos agentes reaccionaron.

Como toda forma de conocimiento, la historia tiene pretensión de objetividad. Al comienzo de este trabajo planteamos y fundamentamos que la objetividad sólo podía ser situada (por oposición a absoluta). Retomando los análisis de Megill, podemos decir que la historia se propone una forma de objetividad "disciplinaria": "[l]a objetividad disciplinaria pone el énfasis en criterios de juicio que no son universales, sino particulares [...] se refiere a la pretensión que tienen los practicantes de una disciplina en particular sobre la autoridad que poseen en su área de competencia" (MEGILL 2007, p. 117-118). Tamm agrega: "la idea de objetividad disciplinaria es pragmática por naturaleza" (TAMM 2014, p. 280). Según Kuukkanen, la objetividad en la ciencia histórica está asociada al "ideal que las comunidades científicas deben tratar de alcanzar", ideal que se expresa en "actos de habla racionales y argumentativos" (KUUKKANEN 2015, p. 195 y 192). En todos estos casos, la objetividad de la historia científica está fuertemente asociada a los cánones de argumentación, al trabajo con las pruebas y a la formulación de textos, criterios todos ellos que valen en cuanto son aceptados por la comunidad de expertos. Daston señala que la objetividad comienza a ser un elemento central del método histórico hacia mitad del siglo XIX, momento en que el famoso pasaje I.22 de Tucídides (sobre el tratamiento de los discursos) se transforma en objeto de atención y discusión (DASTON 2007, p. 33-36). Para entender cómo funciona la objetividad en el conocimiento histórico, nos parece 
necesario proponer un doble sentido de este concepto según se aplique al conocimiento producido o al comportamiento de la historiadora.

Los productos del conocimiento histórico de los cuales puede predicarse su objetividad son aquellas interpretaciones que se expresan en una obra histórica. La obra histórica es un artefacto lingüístico que, en general, se estructura como una narración, es decir, posee comienzo, medio y final. La vinculación entre narración e historiografía se puso de manifiesto en la Modernidad. Como lo señala Koselleck al analizar el surgimiento y expansión del término Geschichte, a la historia se le pidió cada vez más una estructura narrativa (KOSELLECK 2006). La tesis generalmente aceptada es la de que el surgimiento de la historia narrativa está estrechamente vinculado con el origen del Estado. Según Hegel, la historia "objetiva" surge en aquellas comunidades que han constituido un Estado, el cual, simultáneamente, se transforma en el tema de las narraciones históricas (HEGEL 1975). Como señala Lorenz: "el discurso de la historia 'objetiva' y el discurso del Estado/nación estuvieron íntimamente conectados desde la segunda mitad del siglo XIX" (LORENZ 2015, p. 215). La idea de que el carácter narrativo es inherente al conocimiento histórico ha sido cuestionada por algunas corrientes que han propuesto modelos alternativos de escritura para la presentación de las interpretaciones. El caso paradigmático lo constituye la Escuela de Annales. Para nuestra argumentación, no es una cuestión central si el conocimiento histórico debe necesariamente poseer una estructura narrativa, por lo que no nos ocuparemos de ella.

En lo que sigue, nos resultará útil retomar el concepto que Danto propone de las que denomina "estructuras temporales". Éstas permiten a la historiadora vincular diversos eventos bajo una misma definición ("Renacimiento" sería un buen ejemplo de estructura temporal en cuanto cubre muchos eventos de distinta categoría que ocurrieron durante un período de tiempo). Esas estructuras temporales son el resultado de las decisiones teóricas que toman los historiadores y es a partir 
de ellas que se recorta el universo de las explicaciones que podrán ser admisibles (DANTO 1985). Podemos ahora recurrir a un argumento clásico para justificar este papel activo de la historiadora: el pasado como tal no es ya un objeto existente, lo que podemos conocer sobre él es el resultado de los restos que hallemos y de los modos en que los interpretemos. No habría forma por medio de la cual la historiadora podría chequear sus interpretaciones contra el "pasado mismo" de manera que le permitiera determinar cuán objetivas son.

Es evidente el impacto que esas afirmaciones tienen sobre la posibilidad de la objetividad en la historia en la medida en que el objeto de la investigación no parece poder postularse de manera independiente de la investigación misma. Podría decirse que la propia investigación lo constituye. Una posición como ésa es la sostenida por Hayden White, para quien las narraciones históricas le adjudican al pasado una estructura que, en verdad, no posee. Antes que mostrar "el pasado tal cual es", la narración histórica le provee de un orden que, dice White, sólo poseen nuestros sueños (WHITE 1992). En consecuencia, los acontecimientos históricos no serían eventos discretos de la realidad pasada, objeto de las interpretaciones históricas, sino una abstracción del contenido de las oraciones que componen la narración. Tal es la definición que propone Ankersmit de las que denomina "substancias narrativas", de modo tal que los textos históricos versarían sobre esas sustancias narrativas que sólo existen en un mundo lingüístico (ANKERSMIT 1983, p. 28).

Para salvar los riesgos de idealismo lingüístico que parecen acechar hace falta recurrir al concepto de "prueba histórica", mediante el cual podemos referirnos a aquellos elementos empíricos sobre los que trabaja la historiadora. Se trata de los restos materiales del pasado (piedras talladas, textos, partes de una urna funeraria, ropa, huesos, etc.), cuya interpretación se expresa en una descripción explicativa del pasado que dejó esos restos. Retomando el clásico y aún inspirador análisis realizado por R. G. Collingwood diríamos con él que la historia se 
ocupa de estudiar eventos "inaccesibles a nuestra observación y estudiarlos inferencialmente, abriéndonos paso hasta ellos a partir de algo accesible a nuestra observación y que el historiador llama 'prueba histórica'" (COLLINGWOOD 1982, p. 244). ${ }^{3}$ También dice Ginzburg que los historiadores "nunca toman una aproximación directa a la realidad. Su trabajo es necesariamente inferencial" (GINZBURG 1991, p. 295).

El trabajo de la historiadora es, entonces, interpretar los restos históricos (todo aquel material empírico que le pueda servir de prueba) a través de la propuesta de hipótesis acerca de su finalidad, sentido o propósito. Los transforma, así, en las pruebas históricas sobre las que basa la interpretación que habrá de expresar lingüísticamente. Podríamos decir que la obra histórica constituye una interpretación de doble espesor. Contiene un primer nivel de interpretación, dirigido a los restos históricos que constituye como pruebas; y un segundo nivel que da cuenta del pasado del cual provienen esos restos.

La interpretación de la prueba nunca se da de manera aislada, sino que surge de las posibles relaciones que esa prueba pueda tener con otras. Es, así, un eslabón en un conjunto de interpretaciones con las que establece múltiples relaciones en la búsqueda de dar cuenta del pasado. Una tablilla de arcilla con ciertas marcas sobre ella puede interpretarse como una pieza que contiene una forma de escritura, la que, a su vez, puede interpretarse como la formulación de un problema matemático, el cual hay que entender para volver razonable la solución que se sugiere en la tablilla. Se da una compleja interacción entre información empírica (la antigüedad de la tablilla, los materiales de los que está compuesta) y conocimientos de una escritura antigua, además de un conocimiento específico de matemática y sobre la propia cultura a la que la tablilla pertenece. ${ }^{4}$

Proponemos ahora señalar cuáles son los rasgos de una interpretación para ser considerada objetiva. En primer lugar, la interpretación de la prueba histórica disponible debe ajustarse a los siguientes requisitos: incluye la información relevante para el caso en estudio, es coherente con la información ya disponible 
y aceptada $\mathrm{y}$, en caso de contradecirla, permite formular mejores respuestas que otras interpretaciones posibles. En segundo lugar, como la interpretación de la prueba se incluye en la obra histórica, que es, a la vez, una interpretación de un evento o parte del pasado, la obra histórica será objetiva en cuanto exprese de manera legible y coherente su respuesta a la pregunta que se propone responder acerca de qué fue lo que ocurrió.

Es necesario formular todavía una aclaración: la prueba histórica lo es con relación a una interpretación, por lo que se presenta un vínculo circular entre ambas, pues es la interpretación la que anticipa qué puede servir de prueba. Cierto elemento empírico puede ser considerado como resto histórico a interpretar según alguna idea preliminar de la interpretación que lo volverá significativo. Volviendo a Collingwood: "hasta que se haya planteado una pregunta, no hay prueba histórica para ella" (COLLINGWOOD 1994, p. 486). También: "el único conocimiento que la historiadora reclama es el conocimiento de la respuesta que la prueba histórica en su posesión da a la pregunta que está planteando. Y la pregunta es ella misma relativa a la prueba histórica, como la prueba histórica lo es a la pregunta". 5

Como dijimos más arriba, la obra histórica condensa una doble interpretación, la de la prueba histórica y la del pasado del cual es prueba. Se trata de dos niveles de interpretación imbricados, pues uno guía al otro, del mismo modo en que ciertos supuestos teóricos guían la búsqueda y lectura de los datos en las ciencias naturales. Llegados hasta aquí, la objetividad que proponemos supone pensar la dependencia conceptual de la prueba histórica (empírica) respecto de la interpretación (teórica). Por si hace falta, aclaramos que la historiadora no crea ni inventa sus pruebas históricas. Lo que queremos remarcar es la estrecha dependencia entre un elemento empírico determinado que es tomado como prueba histórica y el marco de interpretación que puede "verlo" como tal. Hacemos hincapié en que la objetividad, antes que una característica
5 Estas citas provienen del manuscrito "Lectures on the Philosophy of History", de 1928, incluido en (COLLINGWOOD 1994). 
de un contenido del conocimiento tomado aisladamente, es aquella que se puede determinar en comparación con otros conocimientos que constituyen el trasfondo de la disciplina histórica.

Habíamos señalado un segundo sentido de la objetividad para hablar del comportamiento de la historiadora. Diremos que su comportamiento es objetivo cuando se ajusta a los siguientes requisitos: exhibe las pruebas históricas en las que basa su interpretación, explicita sus hipótesis, expone la cadena de razonamientos que la llevaron a concluir en su interpretación y está abierta a las críticas que se le pueden proponer. Se trata de un comportamiento pasible de ser considerado científico de acuerdo con las reglas propias de la disciplina histórica con relación al trabajo con la evidencia y a los resultados esperables en el marco de una investigación historiográfica (BEVIR 1994; KUUKKANEN 2015, p. 194). El comportamiento objetivo de una historiadora se mide en el contexto de la práctica de la historia científica aceptada para exponer y justificar los resultados de la investigación. Nos parece adecuado, también, agregar dos criterios adicionales: la disposición de la historiadora a considerar la evidencia disponible como provisoria y la toma de conciencia de que los cánones de la disciplina reproducen en medida importante los modelos de interpretación disponibles en su contexto contemporáneo.

Si consideramos ahora bajo esta nueva luz nuestro ejemplo de las momias del Llullaillaco, veremos que es posible interpretar de manera objetiva -según los dos sentidos aquí presentadosqué sucedió con esos niños. En primer lugar, los cuerpos y demás elementos empíricos hallados se vuelven comprensibles si se los considera en el marco de la práctica social de la "capacocha", propia del contexto histórico en el que ocurrieron las muertes de los niños. En la medida en que esa práctica es conocida por la comunidad de expertos y es aceptable la explicación según la cual esas muertes son una consecuencia de ella, se garantiza una interpretación objetiva de por qué había momias en ese lugar de la montaña; aunque no se trate de la única explicación 
ni necesariamente de la última. Desde el punto de vista del comportamiento de la historiadora, podremos considerarlo objetivo en la medida en que se ajuste a los parámetros de la práctica histórica y arqueológica tal como se acepta en la actualidad. La historiadora deberá mostrar que incluye en su explicación toda la prueba histórica relevante (los elementos hallados en las tumbas), que no deja fuera de su explicación otros elementos que son conocidos y aceptados (las pruebas que documentan que la práctica de la "capacocha" involucraba fundamentalmente a niños y jóvenes, los registros que dan cuenta de que se trataba de una práctica social común en el Imperio Inca, asociada a una compleja red de reconocimiento social, etc.). Y, finalmente, puede proveer una explicación que es consistente con el conocimiento aceptado sobre la vida social y religiosa de los pueblos originarios (o bien, si lo contradice, puede proporcionar una mejor explicación).

La objetividad es, así, un logro colectivo de la comunidad de historiadores a partir de prácticas reconocidas y admitidas como constitutivas de esa comunidad en la producción de un conocimiento que se admite como válido según sus condiciones de generación y justificación. El contexto de una práctica científica no es autónomo del marco social mayor en el que se inserta, de ahí que hayamos agregado los dos últimos requisitos.

Esta idea de objetividad es deudora en medida importante de la noción de consenso, puesto que las prácticas $-y$ los conocimientos que ellas producen - son consideradas objetivas en relación con lo aceptado por una comunidad en un momento determinado del desarrollo de una disciplina, lo que Agazzi denomina el "a priori histórico de la ciencia" (AGAZZI 2014, p. 313-319). Ahora bien, ese consenso no se mantiene incólume: puede mostrar grietas y ser objeto de críticas. Entonces, ¿qué ocurre cuando se generan rupturas en el consenso y se denuncia la existencia de un sesgo que limita la investigación detrás del ideal de objetividad admitido? Las discusiones acerca de qué prueba aceptar, cómo "leerla", qué hipótesis se ponen en 
juego y, finalmente, cómo se garantiza que una interpretación propuesta sea "objetiva" en los sentidos indicados en este trabajo no son una situación excepcional en la historia. Más bien lo contrario. En lo que sigue, trataremos de mostrar por qué nuestra definición de objetividad (como objetividad situada que se refiere al conocimiento y al comportamiento de los investigadores) permite dar cuenta de los aspectos más propios de la disciplina histórica.

\section{Objetividad: jqué objetividad?}

Las rupturas que se han producido en la hegemonía de una historiografía narrativa de corte documentalista y enfocada en el estudio de los fenómenos políticos han traído aparejada una discusión acerca de cómo se fundamenta el conocimiento histórico y cuándo puede decirse que se produce un conocimiento de calidad acerca del pasado. Más allá de las críticas que algunas corrientes historiográficas le formularon a la historia tradicional, ellas no están dispuestas a abandonar el ideal de objetividad como una exigencia a la que debe ajustarse tanto el resultado del trabajo histórico - las interpretaciones sobre el pasado- como el comportamiento de los historiadores. Más bien han procurado re-definirlo. Entre las (numerosas) corrientes críticas a la historia tradicional, podemos ubicar a la mencionada Escuela de Annales y también a la historia social, a las historiografías feminista y decolonialista, entre otras (BURKE 1993, SPIEGEL 2006).

El énfasis en que la historia se concentra en un estudio desapasionado de sus "fuentes" produce lo que D. LaCapra ha caracterizado como "objetificación", es decir, un abordaje de los hechos que vacía de elementos subjetivos al objeto de estudio e ignora el compromiso afectivo del historiador con él. Compromiso que será inevitable y necesario cuando se aborden ciertos acontecimientos históricos. A diferencia de la objetividad, esta posición se concentra solo en la contrastación empírica de datos y supone una separación completa entre quien realiza la investigación y su objeto de estudio, que 
es otro sujeto. Este abordaje es particularmente ineficaz cuando se propone estudiar los denominados acontecimientos

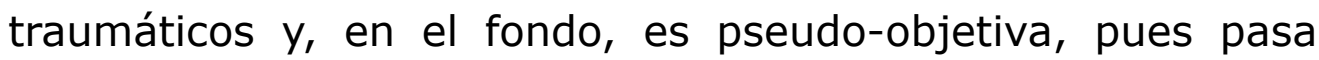
por alto un elemento definitorio del objeto del conocimiento histórico: su condición de sujeto (LACAPRA 2005, p. 117). En esa perspectiva objetificante puede identificarse la operación de una metáfora:

tan seductora para la mente académica de un observador extrahistórico que examinara la historia como si fuera un fenómeno no humano, [esa metáfora] es errónea. Podemos orientarnos hacia la objetividad, pero no podemos orientarnos hacia una objetividad inter-estelar, extra-humana, que sería extra-sensorial, extra-moral y extra-racional (THOMPSON 1981, p. 347).

Como también señala LaCapra, esta perspectiva objetificadora está asociada a cierta "insensibilidad" que pasa por alto "las situaciones imposibles" en las que muchas veces los agentes históricos están situados (LACAPRA 2005, p. 117). Una historia de la esclavitud puede escribirse considerándose sólo sus características de fenómeno económico (en un sentido liberal o materialista). Pero, al hacerlo, perderemos de vista las dimensiones subjetivas de la experiencia de la esclavitud y, además, perderemos de vista el carácter de agentes de aquellos sometidos a la esclavitud, es decir, su condición de seres activos, sujetos de padecimientos y también generadores de alternativas.

No estamos defendiendo una historiografía basada exclusivamente en los agentes históricos, que transformaría el pasado en una empresa voluntarista. Lo que intentamos señalar es que la condición de agentes de quienes habitaron el pasado es un elemento central de su reconocimiento como sujetos. Incluso quienes soportaron condiciones de extrema restricción a sus capacidades de actuar podrán seguir siendo agentes históricos que buscaron resistir a las situaciones deshumanizantes en las que se vieron envueltos. Piénsese 
en el caso de los prisioneros de un campo de concentración, hasta en esas condiciones, algunos de ellos fueron capaces de llevar adelante algún tipo de acción, como intercambiar objetos, organizar una tarea o compartir una ración. Dice Levi, rememorando su experiencia después de su primera semana en Auschwitz: "sabemos ahora que no es lo mismo recibir un cucharón de sopa de la superficie que del fondo del caldero y ya estamos en condiciones de calcular, basándonos en la capacidad de los distintos calderos, cuál es el sitio más conveniente al que aspirar cuando hay que hacer la cola" (LEVI 2005, p. 55). Y al recordar las enseñanzas de otro prisionero: "porque el Lager es una gran máquina para convertirnos en animales, nosotros no debemos convertirnos en animales; que aun en este sitio se debe sobrevivir, para contarlo, para dar testimonio; y que para vivir es importante esforzarse por salvar al menos el esqueleto, la armazón, la forma de la civilización" (p. 64). De esta manera, vemos en Levi, según señala LaCapra, "el arduo proceso" de pasar de "víctima" a "sobreviviente y agente" y no sólo el residuo biológico de una máquina de destrucción (LACAPRA 2006, p.235). ${ }^{6}$

Una interpretación histórica que no recoja esos esfuerzos de los agentes históricos sería claramente limitada y su objetividad, dudosa. Las condiciones humanas de los personajes históricos, sus circunstancias materiales, sus modos de experimentarlas, su condición de género o de clase, sus agencias, entre muchos otros elementos, conforman dimensiones del complejo objeto del conocimiento histórico. La historiadora puede interesarse sólo en una parte del pasado o en algunas de sus dimensiones, pero ese recorte no supone la negación de aquellos otros que no constituyen el foco de su interés. Además, ese recorte debe justificarse en la medida en que es una decisión teórica y, por lo tanto, debe ajustarse a los requisitos que hemos indicado para poder caracterizar el comportamiento de la historiadora como objetivo. Nos parece adecuado repensar aquí el "postulado de adecuación" que planteaba Schutz, retomando a Weber, cuyo cumplimiento habría de garantizar "la compatibilidad de las construcciones del científico social [en nuestro caso, la 
historiadora] con las de la experiencia de sentido común de la realidad social" (SCHUTZ 1974, p. 68). Habremos de entender este postulado como una indicación de que las interpretaciones y explicaciones propuestas no sólo satisfagan los requisitos de adecuación a la información empírica disponible, sino que salvaguarden el carácter activo (en la medida adecuada según las circunstancias) de los agentes históricos involucrados.

\section{Conclusión}

¿Por qué es valiosa la objetividad en la historia? En relación con la historiadora, porque, si su comportamiento es objetivo, puede garantizar que las conclusiones que presenta no derivan de sus preferencias personales, sino que son el resultado de un método de trabajo que puede ser replicado de manera independiente por otros a partir de la información disponible. Un comportamiento objetivo será, entonces, un comportamiento virtuoso en términos epistémicos, por contraposición a un comportamiento incorrecto, desleal o tramposo (DASTON; GALISON 2007, DASTON 2014). Y en relación con el conocimiento, porque, cuando éste es objetivo, provee información sobre su objeto de análisis que podrá probarse como correcta bajo las condiciones en las que se generó, aunque pueda ser falible considerada en otro momento o desde otra perspectiva teórica.

A modo de cierre, podríamos decir que la historia objetiva es mejor que la que no lo es porque nos permite revisar nuestra propia incidencia como investigadores en el objeto de estudio. Mediante el intercambio permanente con otros, la apertura a revisar nuestras interpretaciones de las pruebas históricas y la aceptación de nuevas pruebas o la reformulación de las antiguas, intentamos que nuestras explicaciones y descripciones del pasado no sean simples reflejos de nuestros condicionamientos sociales y culturales o de nuestras preferencias. A la vez, tenemos claro que la investigación histórica trata con objetos que no están dados de una vez y para siempre, sino que dependen de los puntos de vista con los cuales los abordamos. 
Rechazar el conocimiento histórico porque no admite una objetividad absoluta (quimérica, pues sería sin sujeto, sin condiciones, atemporal) significaría también el rechazo de lo que hemos logrado saber efectivamente sobre el pasado, que es cada vez más y mejor. $Y$, como el campesino que aguardaba la autorización del guardián en el cuento kafkiano, envejeceríamos mientras esperamos aquello que nunca vamos a lograr. 


\section{REFERENCIAS}

AGAZZI, Evandro. Scientific Objectivity and Its Contexts. London: Springer, 2014.

ABEL, Theodore. La operación llamada Verstehen. In: HOROWITZ, IrvingLouis. (ed.) Historia y elementos de la sociología del conocimiento. Traducción de Noemí Rosenblatt. Buenos Aires: Eudeba, 1964. p.185-196.

ANKERSMIT, Frank. Narrative Logic. A Semantic Analysis of the Historian's Language. The Hague: Martinus Nijhoff Publishers, 1983.

BEVIR, Mark. Objectivity in History. History and Theory, v. 33, n. 3, p. 328-344, 1994. Disponible en: https:// www.jstor.org/stable/2505477?origin=JSTOR-pdf\&seq=1. Consultado el: 6 mayo 2019.

CERUTI, María Constanza. Elegidos de los Dioses: identidad y estatus en las víctimas sacrificiales del volcán Lullaillaco, Boletín de Arqueología, PUCP, n 7, p.263-275, 2003. Disponible en: http://revistas.pucp.edu.pe/index.php/ boletindearqueologia/article/view/1993. Consultado el: 4 abr. 2020.

CERUTI, María Constanza. Los niños del Llullaillaco y otras momias andinas: salud, folclore, identidad. Scripta Ethnologica, v. XXXIV, p.89-104, 2012. Disponible en: http://www.redalyc.org/articulo. oa?id=14828711005. Consultado el: 15 ago. 2019.

COLLINGWOOD, Robin. G. Idea de la historia. Traducción de Edmundo O'Gorman y Jorge Hernández Campos. México: FCE, 1982. 
COLLINGWOOD, Robin. G. Outlines of a Philosophy of History [1928]. In: COLLINGWOOD, Robin. The Idea of History, edición revisada por Jan Van der Dussen. Oxford, New York: Oxford University Press, 1994. p.437-496.

COSMAI, Natalia P., FOLGUERA, Guillermo y OUTOMURO, Delia. Restitución, repatriación y normativa ética y legal en el manejo de restos humanos aborígenes en Argentina, Acta Bioethica. v. 19, n. 1, p. 19-27, 2013. Disponible en:https://scielo.conicyt.cl/scielo.php?script $=$ sci_ arttext\&pid=S1726-569X2013000100003\&Ing=en\&nrm=is o\&tlng=en. Consultado: 18 mar. 2020.

DANTO, Arthur. Analytical Philosophy of History. New York: Columbia University Press, 1985.

DASTON, Lorraine; GALISON, Peter. Objectivity, New York: Zone Books, 2007.

DASTON, Lorraine. Objectivity and Impartiality: Epistemic Virtues in the Humanities. In: BOD, Rens, MAAT, Jaap \& WESTSTEIJN, Thijs. (eds.), The Making of the Humanities, vol. III, Amsterdam: Amsterdam University Press, 2014. p. 27-42.

DILTHEY, Wilhelm. Crítica de la razón histórica. Traducción de Caros Moya Espí, edición de Hans Ulrich Lessing. Barcelona: Península, 1986.

GINZBURG, Carlo. Checking the Evidence: The Judge and the Historian. In: GINZBURG, Carlo. Questions of Evidence. Proof, Practice and Persuasion across the Disciplines. Chicago \& Londres: University of Chicago Press, 1991. p.290-303.

HEGEL, Georg W.F. Lecciones sobre la filosofía de la historia universal. Traducción de José Gaos. Madrid: Alianza Universidad, 1975. 
JAMES, Daniel. Historias contadas en los márgenes. La vida de Doña María: Historia oral y problemática de géneros, Entrepasados. Revista de historia, año II, no 3, p.7-24, 1992.

JAMES, Daniel. Doña María. Historia de vida, memoria e identidad política. Buenos Aires: Manantial, 2004.

KLIMOVSKY, Gregorio. Las desventuras delconocimiento científico. Una introducción a la epistemología. Buenos Aires: A-Z editora, 1994.

KUUKKANEN, Jouni-Matti. Postnarrativist Philosophy of Historiography. New York: Palgrave MacMillan, 2015.

KOSELLECK, Reinhardt. Historia/historia. Traducido por Antonio Gómez Ramos. Madrid: Trotta, 2006.

LACAPRA, Dominick. Escribir la historia, escribir el trauma. Traducción de Elena Marengo. Buenos Aires: Ed. Nueva Visión, 2005.

LACAPRA, Dominick. Sobre el acontecimiento límite: una interpelación a Agamben. In: LACAPRA, Dominick. Historia en tránsito. Traducción de Teresa Arijón. Buenos Aires: Fondo de Cultura Económica, 2006. p. 195-259.

LEVI, Primo. Si esto es un hombre. In: LEVI, Primo. Trilogía de Auschwitz. Traducción de Pilar Gómez Bedate. Barcelona: El Aleph, 2005. p. 31-245.

LORENZ, Chris. Despegado del tiempo. O la repentina presencia del pasado. In: LORENZ, Chris. Entre filosofía e historia, vol. 1. Traducción de Omar Acha. Buenos Aires: Prometeo Editorial, 2015. p. 207-250.

MEGILL, Alan. Historical Knowledge. Historical Error: A Contemporary Guide to Practice. Chicago: The University of Chicago Press, 2007. 
MIGNONE, Pablo. Illas y Allicac. La Capacocha del Llullaillaco y los mecanismos de ascenso social de los "Inkas de privilegio". Boletín del Museo Chileno de Arte Precolombino, v. 20, n. 2, p. 69-87, 2015.Disponible en: https://scielo.conicyt.cl/scielo.php?script=sci arttext\&pid=S0718-68942015000200005\&Ing=en\&nrm=i so\&tlng=en. Consultado el: 15 ago. 2019.

NAGEL, Ernest. Problemas metodológicos de las ciencias sociales. In: NAGEL, Ernest. La estructura de la ciencia. Problemas de la lógica de la investigación científica. Traducción de Néstor Míguez. Barcelona: Paidós, 2006. p. 581-652.

POPPER, Karl. Epistemología sin sujeto cognoscente. In: POPPER, Karl. Conocimiento objetivo. Traducción de Carlos Solís Santos. Madrid: Tecnos, 1974. p. 106-146.

PUTNAM, Hilary. Razón, verdad e historia. Traducción de José Miguel Esteban Cloquell. Madrid: Tecnos, 2006.

SCHUTZ, Alfred. El problema de la realidad social. Traducción de Néstor Míguez.Buenos Aires: Amorrortu Editores, 1974.

SHARPE, Jim. Historia desde abajo. In: BURKE, Peter. (ed.) Formas de hacer historia. Traducción de José Luis Gil Aristu, Madrid: Alianza Universidad, 1993. p. 38-58.

SPIEGEL, Gabrielle. La historia de la práctica: nuevas tendencias en historia tras el giro lingüístico, Ayer, 62, p. 19-50, 2006. Disponible en: http://revistaayer.com/sites/ default/files/articulos/62-1-ayer62_MasAllaHistoriaSocial_ Cabrera.pdf. Consultado: 18 junio 2019.

TAMM, Marek. Truth, Objectivity and Evidence in History Writing. Journal of the Philosophy of History, $v$. 8, n. 2, p.265-290, 2014. Disponible en: http://www. culturahistorica.es/tamm/truth.pdf. Consultado el: 3 oct. 2019. 
THOMPSON, Edward P. An Open Letter to Leszek Kolakowski. In: THOMPSON, Edward P. The Poverty of Theory and Other Essays, London: Merlin Press, 1981. p. 303-402.

WHITE, Hayden. El valor de la narrativa en la representación de la realidad. In: WHITE, Hayden. El contenido de la forma. Narrativa, discurso y representación histórica. Traducción de Jorge Vigil Rubio. Barcelona: Paidós, 1992. p. 17-39. 
NOTA DEL AUTOR

\section{Rosa E. Belvedresi}

rosabelvedresi@gmail.com

Instituto de Investigaciones en Humanidades y Ciencias Sociales

Consejo Nacional de Investigaciones Científicas y Técnicas

Universidad Nacional de La Plata

La Plata

Buenos Aires

Argentina

\section{DIRECCIÓN POSTAL}

Rosa E. Belvedresi

Universidad Nacional de La Plata

Facultad de Humanidades y Ciencias de la Educación

Calle 51 e/ 124 y 125

(1925) Ensenada

Buenos Aires - Argentina

\section{AGRADECIMIENTOS}

Una versión muy preliminar de este trabajo fue leída en las XXX Jornadas de Epistemología e historia de la Ciencia (Córdoba, Argentina, 2019). Agradezco las sugerencias que recibí de quienes forman parte de mi equipo de investigación en la Facultad de Humanidades y Ciencias de la Educación de la Universidad Nacional de La Plata.

\section{FINANCIACIÓN}

No se declaró financiación.

\section{CONFLICTO DE INTERESES}

Sin conflicto de interés declarado.

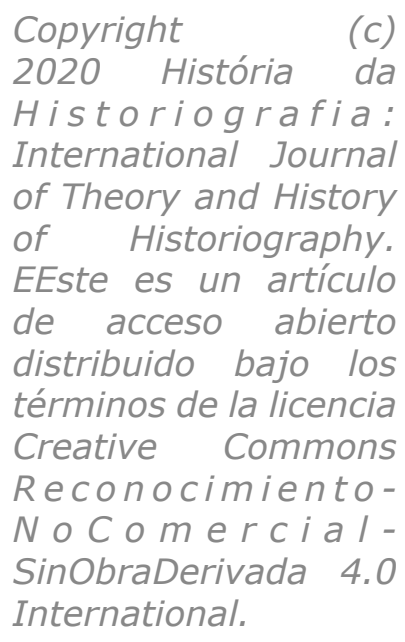

